\title{
Surgical Outcomes of Idiopathic Macular Epiretinal Membrane Peeling
}

\author{
Uzma Haseeb1, Aziz Ur Rehman1, Abdul Fattah Memon1, Muhammad Haseeb² and Nasir Memon1
}

\begin{abstract}
Objective: To evaluate the surgical outcomes of idiopathic macular epiretinal membrane (IERM) peeling in terms of visual acuity and macular thickness.

Study Design: Observational cross-sectional study.

Place and Duration of Study: Al-Ibrahim Eye Hospital, Karachi, from June 2017 to February 2018.

Methodology: Patients aged $>50$ years having IERM confirmed with optical coherence tomography (OCT) were included in the study. All patients underwent 3-port pars plana vitrectomy (PPV) followed by epiretinal membrane peeling. Log Mar visual acuity chart was used for documenting visual acuity pre- and postoperatively. OCT was performed for documenting changes in macular thickness pre- and postoperatively. Every patient completed their follow-up of six months.

Results: Mean age of the 43 patients was found to be $59.98 \pm 6.1$ years. Mean pre- and postoperative visual acuity of Log Mar showed $0.59 \pm 0.21$ and $0.33 \pm 0.21$, respectively $(p<0.001)$. Mean macular thickness on OCT pre- and postoperatively were $479 \pm 82.5$ and $315 \pm 82.4 \mu \mathrm{m}$, respectively $(p<0.001)$. In thirty-one $(72.1 \%)$ eyes, there was improvement in best corrected visual acuity (BCVA) postoperatively, 9 (20.9\%) eyes remained stable; whereas, $3(7 \%)$ eyes had decreased visual acuity at final follow-up of six months.

Conclusion: Peeling of IERM is a safe surgical procedure. It is associated with significant improvement in best corrected visual acuity postoperatively along with improvement in anatomical outcomes in terms of decrease macular thickness as measured by OCT.
\end{abstract}

Key Words: Epiretinal membrane, Visual acuity, Pars plane vitrectomy, Optical coherence tomography.

\section{INTRODUCTION}

Epiretinal membrane (ERM) is an avascular, fibrocellular membrane that is found on the inner retinal surface and is attached to internal limiting membrane. In initial stages, it is translucent and found on the surface of internal limiting membrane, known as cellophane maculopathy. Macular pucker is an advanced stage. Patients with ERM present mostly over the age of 50 years and usually affected with difference in severity in both eyes. ${ }^{1}$ The prevalence of ERM increases as age increases, varying from $2.2 \%$ to $28.9 \%$, depending on the population being studied.2,3

ERMs can be found in young patients who are suffering from some ocular diseases like previous retinal detachment, intraocular inflammation or after trauma. Some studies documented the presence of ERM up to the age of 40 years. ${ }^{4}$

The majority of ERM cases remain stable and do not require therapy. In patients who have areas of vitreo-

\footnotetext{
1 Department of Ophthalmology, Al-Ibrahim Eye Hospital, Karachi, Pakistan

2 Department of Ophthalmology, Al-Ain Institute of Eye Diseases, PECHS, Karachi, Pakistan

Correspondence: Dr. Uzma Haseeb, Department of Ophthalmology, Al-Ibrahim Eye Hospital, Memon Goth Road, Old Thana, Gadap, Karachi, Pakistan

E-mail:uzma_123us@yahoo.com
}

Received: May 04, 2018; Accepted: November 07, 2018 macular traction (VMT) of $1500 \mu \mathrm{m}$ or less, spontaneous release of traction from the macula occurs in approximately $30-40 \%$ of eyes over one to two years, which usually leads to improvement of the metamorphosia and visual acuity. On an average, approximately $80 \%$ of patients with ERM or VMT will improve by at least two lines of visual acuity following vitrectomy surgery. ${ }^{5}$

With unclear pathogenesis, IERM mainly occurs in patients beyond 50 years. The morbidity in patients of 50 years is $2 \%$, while in 75 years it is $20 \%$. It may result in the vision decay, metamorphosia, macular edema, macula transformation, macular retinal ruffle, vessel transformation and distortion, and even retinal tear from traction. ${ }^{6}$ ERM that develops spontaneously and does not associate with any other ocular disease or surgery, is termed as idiopathic. ${ }^{7}$ Symptomatic ERM is treated only with vitrectomy, followed by peeling of the epiretinal membrane.

Clinically, ERM may present as benign asymptomatic disorder or as debilitating metamorphosia and central vision loss. ERM related symptoms, mostly metamorphosia, may affect patient life quality associated with vision. 8

The diagnosis and classification of ERM has traditionally been based on clinical examination findings. However, modern imaging technologies have proved to be more sensitive for diagnosis of ERM and its associated complications. Spectral-domain optical coherence tomography (SD-OCT) with three-dimensional reconstruction, is used for this purpose. ${ }^{9}$ 
The present study was conducted to evaluate the surgical outcomes of epiretinal membrane peeling in terms of visual acuity and macular thickness with the help of Log Mar chart and optical coherence tomography (OCT), respectively.

\section{METHODOLOGY}

Ethical approval was taken from the Institute's Research Ethical Committee (REC). An informed consent taken from all the patients included in this study. This was an observational cross-sectional study with non-probability convenience sampling technique. The study was carried out at Al-Ibrahim Eye Hospital, Karachi, from June 2017 to February 2018. Every patient completed their followup for six months.

Inclusion criteria were all the patients diagnosed with IERM on slit lamp bio-microscopy and confirmed by OCT. Presence of metamorphosia determined subjectively and by Amsler grid chart, macular thickness $>250 \mu \mathrm{m}$, age $\geq 50$ years, eye examinations including measurement of the BCVA of Log Mar $<0.4$, anterior and posterior segment examination, photograph of fundus, fundus fluorescein angiography and OCT. Patients with ERM secondary to ocular diseases like retinal vascular occlusion, retinal detach-ment, trauma or diabetes were not included in the study. Patients with VMT were also included in the study as VMT with ERM is considered a variant of IERM by author. Those who did not give consent were also excluded from the study.

All patients underwent 3-port PPV followed by epiretinal membrane peeling. Log Mar chart was used for taking vision. BCVA was taken from all the patients pre- and postoperatively. The categorization of visual acuity was noticed in terms of improvement, stable or decrease vision. OCT was performed at each step for documenting macular thickness secondary to ERM after surgery.

SPSS for Windows version 20.0 (SPSS Inc., Chicago, IL, USA) was used for data analysis. Mean and standard deviations were calculated for quantitative variables like age of the patients, visual acuity and OCT values. Frequencies and percentages were calculated for gender and visual acuity status determination (Improve, Stable or Worse). Paired sample t-test was used to see the difference between preoperative and postoperative findings of visual acuity (Log Mar) and OCT examination. $\mathrm{P} \leq 0.05$ was considered to be statistically significant.

\section{RESULTS}

Forty-three eyes of 43 patients diagnosed with IERM were examined for this study. Mean age of the patient was found to be $59.98 \pm 6.1$ years with the range of $50-70$ years. Out of them, $18(41.9 \%)$ were males and $25(58.1 \%)$ were females. Mean pre- and post-visual acuity of Log Mar showed $0.59 \pm 0.21$ and $0.33 \pm 0.21$, respectively with significant $p$-value of $<0.001$. Mean macular thickness on OCT pre and post were $479 \pm 82.5$ and $315 \pm 82.4 \mu \mathrm{m}$, respectively, with statistically significant $p$-value $(<0.001)$. The outcomes of pre- and post-visual acuity were measured in the categories of improved, stable and worse/decreased vision. Thirtyone $(72.1 \%)$ eyes showed improvement in visual acuity postoperatively, 9 (20.9\%) eyes had stable visual acuity; whereas, $3(7 \%)$ eyes had decreased visual acuity at the final follow-up of six months.

\section{DISCUSSION}

An epiretinal membrane is fibro-cellular tissue found on the inner retinal surface. The incidence of IERM increases as age increases. Patients with age less than 60 years, the incidence is also less than $4 \%$; but increases to $20 \%$ in patients having age more than 70 years, that is documented in an autopsy study. ${ }^{10}$

This study results showed the effects of epiretinal membrane peeling on visual acuity. Peeling of epiretinal membrane is associated with visual acuity improvement; especially, in patients having poor vision preoperatively, which is in contrast to other diseases that affect macula, like ARMD and diabetes; in which the vision is affected severely and it cannot be reversed.11-13

Idiopathic ERM is most commonly associated with posterior vitreous detachment (PVD). PVD leads to breaks in internal limiting membrane (ILM), causing epiretinal membrane formation. ${ }^{14}$ Breaks in ILM liberates glial cells that proliferate as well as undergo changes into other types of cells and leads to ERM formation. ${ }^{15}$ Traction at the retinal surface is due to cells in collagenous layer. ${ }^{7}$ Prominent retinal striae that can be appreciated clinically are due to contractile properties of myofibroblast with ERM. ${ }^{16}$

In the present study, mean pre- and postoperative visual acuity, checked by using Log Mar chart, showed improvement in vision which ranged from $0.59 \pm 0.21$ to 0.33 \pm 0.21 . A significant $p$-value of $<0.001$ was also seen in the postoperative visual outcome. The visual outcomes improved in $72.1 \%$, remained stable in $20.9 \%$ and decreased in $7 \%$ at final follow-up of six months. Batman also documented the same results that recurrent macular ERMs were not found at final visit. A statistically significant difference was determined between pre- and postoperative BCVA values $(p=0.001) .{ }^{17}$

A study done by Shahzadi et al. reported same results as they were followed up to 6 months and at the end of follow-up, $23(76.7 \%)$ eyes out of 30 gained 2 or more lines of vision. In $5(16.7 \%)$ eyes, BCVA remained same and only $2(6.7 \%)$ eyes showed worsening of vision. ${ }^{18}$

Dawson et al. showed improvement of vision in $69.6 \%$ of cases, $1915.2 \%$ of cases showed worsening, and $15.2 \%$ of cases showed no change in vision. Moisseiev et al. reported an improvement in $65.5 \%$ and worsening in 
$6.9 \%$ of patients. ${ }^{20}$ Another study conducted by Lehpamer showed improvement of visual symptoms in $73 \%$ of patients. 21

Park et al. had showed the results of 44 patients with MP who had PPV followed by peeling of epimacular membrane with/without ILM peeling. ${ }^{22}$ Results showed improvement in BCVA in 19 out of 24 eyes without peeling of ILM; and 20 out of 20 eyes with peeling of ILM.

In the present study, the eyes with poor preoperative BCVA of Log MAR 1.0 or worse, achieved maximum visual improvement of Log MAR 0.3 or more in the postoperative period. Literature review also showed that visual recovery is greater, if the preoperative visual acuity is lower. Dawson also reported that greatest improvements, in postoperative vision, were in those patients who had poor vision preoperatively.

Different clinical studies have classified ERMs on the basis of OCT findings by using different systems. ${ }^{23,24} \mathrm{An}$ OCT-based classification of IERM is based on changes in anatomy of fovea. OCT has greatly helped us in the management of different eye disorders as well as in the diagnosis and classification of vitreomacular interface disorder. OCT has more advantages over clinical examination. 25

As seen in OCT findings, retinal thickness was still thicker than the normal population. Okamoto et al. showed a significant correlation between pre- and postoperative vision-related quality of life and degree of postoperative metamorphosia. In current study, similar results found and mean OCT examination pre and post were 479 \pm 82.5 and $315 \pm 82.4$, respectively with statistically significant $p$-value of $<0.001$.

\section{CONCLUSION}

Peeling of epiretinal membrane is a safe surgical procedure with favorable outcomes, in terms of improvement in BCVA and decrease macular thickness as documented by Log Mar chart and OCT, respectively; thus, improving the vision-related quality of life.

\section{REFERENCES}

1. Khaja HA, McCannel CA, Diehl NN, Mohney BG. Incidence and clinical characteristics of epiretinal membranes in children. Arch Ophthalmic 2008; 126:632-6.

2. You $Q, X u L$, Jonas JB. Prevalence and associations of epiretinal membranes in adult Chinese: the Beijing eye study. Eye (Lond) 2008; 22:874-9.

3. $\mathrm{Ng} \mathrm{CH}$, Cheung $\mathrm{N}$, Wang JJ, Islam AF, Kawasaki R, Meuer SM, et al. Prevalence and risk factors for epiretinal membranes in a multi-ethnic United States population. Ophthalmology 2011; 118:694-9.

4. Benhamou N, Massin P, Spolaore R, Paques M, Gaudric A. Surgical management of epiretinal membrane in young patients. Am J Ophthalmol 2002; 133:358-64.
5. Folk JC, Adelman RA, Flaxen CJ, Hyman L, Pulido JS, Olsen TW. Idiopathic epiretinal membrane and vitreomacular traction preferred Practice Pattern ${ }^{\circledR}$ Guidelines. Am Acad Ophthal 2016; 1:152-81.

6. Chen L, Liu M, Xin AM, Liu Y. A study on change of macular retinal thickness and its relationship with vision before and after operation to idiopathic macular epiretinal membranes. Int J Clin Med 2015; 8:18571-80.

7. McCarty DJ, Muktesh BN, Chicana V, Wang JI, Mitchell P, Taylor HR, et al. Prevalence and associations of epiretinal membranes in the visual impairment project. Am J Ophthalmol 2005; 140:288-94.

8. Ghazi-Nouri SM, Tranos PG, Rubin GS, Adams ZC, Charteris DG. Visual function and quality of life following vitrectomy and Epiretinal membrane peel surgery. Br J Ophthalmic 2006; 90: 559-62.

9. Koizumi H, Spade RF, Fisher YL, Freund KB, Klancnik JM Jr, Yannuzzi LA. Three-dimensional evaluation of vitreomacular traction and epiretinal membrane using spectral-domain optical coherence tomography. Am J Ophthalmol 2008; 145: 509-17.

10. Flaxel CJ, Edwards AR, Aiello LP, Arrigg PG, Beck RW, Bressler NM, et al. Factors associated with visual acuity outcomes after vitrectomy for diabetic macular edema: diabetic retinopathy clinical research network. Retina 2010; 30: 1488-95.

11. Schulze SD, Hesse L. Tissue plasminogen activator plus gas injection in patients with subretinal hemorrhage caused by age-related macular degeneration: Predictive variables for visual outcome. Graefes Arch Clin Exp Ophthalmol 2002; 240: 717-20.

12. Smiddy WE. Clinical applications of cost analysis of diabetic macular edema treatments. Ophthalmology 2012; 119:2558-62.

13. Bu SC, Kuijer R, Li XR, Hooymans JM, Los LI. Idiopathic epiretinal membrane. Retina 2014; 34:2317-35.

14. Girach A, Pakola S. Vitreomacular interface diseases: pathophysiology, diagnosis and future treatment options. Expert Rev Ophthalmol 2012; 7:311-23.

15. Hirokawa H, Jalkh AE, Takahashi M, Takahashi M, Trempe CL, Schepens CL. Role of the vitreous in idiopathic preretinal macular fibrosis. Am J Ophthalmol 1986; 101:166-9.

16. Sebag J, Wang MY, Nguyen D, Sadun AA. Vitreopapillary adhesion in macular diseases. Trans Am Ophthalmol Soc 2009; 107:35-44.

17. Batman $C$, Citrik $M$. The impact of macular surgery in different grades of epiretinal membrane. Int J Ophthalmol 2017; 10: 1877-82.

18. Shahzadi B, Rizvi SF, Latif K, Murtaza F, Naz S. Visual and anatomical outcomes following idiopathic macular epiretinal membrane surgery. J Coll Physicians Surg Pak 2016; 26: 971-4.

19. Dawson SR, Shunmugam M, Williamson TH. Visual acuity outcomes following surgery for idiopathic epiretinal membrane: An analysis of data from 2001 to 2011. Eye (Lond) 2014; 28: 219-24.

20. Moisseiev E, Davidovitch Z, Kinori M, Loewenstein A, 
Moisseiev J, Barak A. Vitrectomy for idiopathic epiretinal membrane in elderly patients: surgical outcomes and visual prognosis. Curr Eye Res 2012; 37:50-4.

21. Lehpamer BP, Carvounis PE. Pars plana vitrectom for symptomatic epiretinal membranes in eyes with $20 / 50$ or better visual acuity. Retina 2015; 35:1822-7.

22. Park DW, Dugel PU, Garda J, Sipperley JO, Thach A, Sneed SR, et al. Macular pucker removal with and without internal limiting membrane peeling: pilot study. Ophthalmology. 2003; 110:62-4.
23. Mori K, Gehlbach PL, Sano A, Deguchi T, Yoneya S. Comparison of epiretinal membranes of differing pathogenesis using optical coherence tomography. Retina 2004; 24:57-62.

24. Hwang JU, Sohn J, Moon BG, Joe SG, Lee JY, Kim JG, et al. Assessment of macular function for idiopathic epiretinal membranes classified by spectral-domain optical coherence tomography. Invest Ophthalmol Vis Sci 2012; 53:3562-9.

25. Konidaris V, Androudi S, Alexandridis A, Dastiridou A, Brazitikos P. Optical coherence tomography-guided classification of epiretinal membranes. Int Ophthalmol 2015; 35:495-501. 